\title{
The small intestine in dermatitis herpetiformis
}

\author{
LIONEL FRY, P. P. SEAH, P. G. HARPER, A. V. HOFFBRAND, AND \\ R. M. H. MCMINN \\ From St Mary's Hospital, London, the Royal Postgraduate Medical School, London, and the \\ Royal College of Surgeons, London
}

SYNOPSIS Small intestinal biopsies from 43 patients with dermatitis herpetiformis have been studied. The diagnosis of dermatitis herpetiformis was made on clinical and histological criteria and the presence of IgA deposits in the uninvolved skin. The macroscopic appearance of the intestinal biopsy was flat in 13, convoluted in 10, leaves only in eight, and fingers and leaves in 12 . Twenty small intestinal biopsies from patients who did not have dermatitis herpetiformis or gastrointestinal disorder showed leaves only in three and fingers and leaves in 17 . The mean total lymphocyte count per 1000 epithelial cells for this control group was $159 \pm \mathrm{SE} 13$; for the dermatitis herpetiformis patients with flat biopsies it was $464 \pm$ SE 27; for the convoluted biopsies $365 \pm$ SE 59; for leaves only $535 \pm$ SE 39 ; and for the fingers and leaves biopsies $301 \pm$ SE 31 . The counts for all four groups are significantly greater than the control group $(P<0.001)$. Three of the 43 patients with dermatitis herpetiformis had lymphocyte counts below 200 per 1000 epithelial cells, and four of our controls had counts greater than 200 but none above 300 .

In the control group the mean counts for lymphocytes per 1000 epithelial cells in the basal position of the intestinal epithelium was $79 \pm \mathrm{SE} 8$; in the dermatitis herpetiformis flat biopsies it was $89 \pm \mathrm{SE} 11$; for the convoluted biopsies $93 \pm \mathrm{SE} 12$; for the leaves only biopsies $121 \pm \mathrm{SE} 18$ and for the fingers and leaves $98 \pm$ SE 13. However, the mean lymphocyte count in the perinuclear position was $81 \pm \mathrm{SE} 7$ for the controls, $362 \pm \mathrm{SE} 23$ for the flat dermatitis herpetiformis biopsies; $251 \pm$ SE 46 for the convoluted specimens; $402 \pm$ SE 43 for the leaves only specimens, and $195 \pm$ SE 25 for the fingers and leaves biopsies. The mean lymphocyte count for the supranuclear position was $0.55 \pm \mathrm{SE} 0.22$ for the control group; $13.7 \pm \mathrm{SE} 2.3$ for the flat dermatitis herpetiformis biopsies; $20.0 \pm \mathrm{SE} 6.9$ for the convoluted biopsies; $14.5 \pm \mathrm{SE} 3.3$ for the leaves only biopsies; and $8.3 \pm$ SE 2.6 for the fingers and leaves biopsies. Thus in gluten-sensitive enteropathy the increase in lymphocytes in the intestinal epithelium is in the perinuclear and supranuclear position. The ratio of basal lymphocytes to peri- and supranuclear lymphocytes appears to be $1: 1$ in normal intestinal epithelium, but approximately 1:4 in the gluten-sensitive enteropathy of dermatitis herpetiformis.

Approximately two-thirds of patients with dermatitis herpetiformis have an abnormal small intestinal mucosa judged by macroscopic appearance and histological features (Marks, Shuster, and Watson, 1966; Fraser, Murray, and Alexander, 1967; Fry, Keir, McMinn, Cowan, and Hoffbrand, 1967). The enteropathy in these patients is similar to that found in adult coeliac disease since it responds to a glutenfree diet (Fry, McMinn, Cowan, Hoffbrand, 1968, 1969; Shuster, Watson, and Marks, 1968; Marks and Whittle, 1969), and relapses on the re-introduction of gluten (Fry et al, 1969). Recently, Gebhard, Katz,

Received for publication 28 June 1974.
Marks, Shuster, Trampani, Rogentine, and Strober (1973) have suggested, on the basis of these findings and of HL-A tissue typing, that there may be two distinct groups of dermatitis herpetiformis patients: the first group, about two-thirds, with a glutensensitive enteropathy, and the second, the remaining third, who show no morphological or histological abnormality of the small intestinal mucosa, and therefore no enteropathy. However, the criteria for the diagnosis of both dermatitis herpetiformis and of gluten-sensitive enteropathy have recently been questioned. Fry and Seah (1974) have shown that previously accepted clinical and histological features of the skin eruption of dermatitis herpetiformis and 
the characteristic response of the rash to dapsone are not in themselves diagnostic. Thus, if only these criteria are used, approximately $20 \%$ of patients who do not have the disorder will be labelled as suffering from dermatitis herpetiformis. Furthermore, Fry and Seah (1974) and Seah, Fry, Mazaheri, Mowbray, Hoffbrand, and Holborow (1973) have shown that the presence of $\operatorname{IgA}$ in the uninvolved skin is an important diagnostic feature of the dermatitis herpetiformis syndrome. In addition, Brow, Parker, Weinstein, and Rubin (1971) showed that a single small intestinal biopsy is not sufficient to exclude an enteropathy in dermatitis herpetiformis since the lesion is often patchy. Thus multiple biopsies may increase the incidence of an enteropathy to over $90 \%$. The incidence may be still higher since Weinstein (1973) found that instillation of a large amount of gluten directly into the upper small intestine (gluten challenge) in dermatitis herpetiformis may elicit morphological abnormalities in a jejunal mucosa of previously normal appearance. Moreover, Fry, Seah, McMinn, and Hoffbrand (1972) have shown that previous criteria for diagnosing gluten-sensitive enteropathy in dermatitis herpetiformis, based on the morphological and histological appearance, are less sensitive than the finding of increased lymphocytic infiltration in the epithelium of the small intestine.

The present paper reports further studies of lymphocytes in the small intestine in patients with dermatitis herpetiformis in which not only the numbers but also the site of the lymphocytes in the intestinal epithelium has been examined. The results show that not only is there an increase in the total number of lymphocytes in the epithelium of the small intestine of patients with gluten-sensitive enteropathy of dermatitis herpetiformis, but also that the distribution of these epithelial lymphocytes differs from the distribution of the lymphocytes in normal intestine.

\section{Patients and Methods}

Small intestinal biopsies were studied from 43 patients ( 21 males and 22 females) with dermatitis herpetiformis. Their ages ranged from 23 to 76 years. The diagnosis of dermatitis herpetiformis was made on: (1) the clinical features, (2) the histological features of the skin lesions, (3) response of the rash to dapsone and relapse on withdrawal of the drug, (4) the presence of IgA in the dermis of the uninvolved skin. In this particular study only the results of a single biopsy from each patient prior to a glutenfree diet are reported.

Small intestinal biopsies from 20 control subjects (seven males and 13 females) were also studied. Their ages ranged from 22 to 73 years. Of these 20 , seven had psoriasis, 11 had eczema, one had pemphigus, and one was a volunteer physician. The patients with eczema and psoriasis had the biopsy carried out to determine if there was any abnormality of the small intestine in those conditions; the patient with pemphigus had a biopsy performed as she had been diagnosed at another hospital as having dermatitis herpetiformis.

\section{Small Intestinal Biopsy}

The biopsy was taken under radiographic control with a Crosby capsule from the duodeno-jejunal flexure. The macroscopic appearance of the biopsy was assessed with a dissecting microscope and the specimens photographed for the record and fixed in formol saline and embedded in wax. Sections $7 \mu$ thick were cut and stained with haematoxylin and eosin.

The epithelial cells and intraepithelial lymphocytes were counted in those parts of the specimen that were suitably orientated, ie, where the epithelium was sectioned in a plane at right angles to the underlying connective tissue. In villous and convoluted specimens, counts were made on the cells of the sides and tips of the villi, and in flat specimens on theo surface cells. No attention was paid to crypt cells which, in both control and gluten-sensitive enterose pathy specimens, show very little cellular infiltration compared with villous cells. Low-power magnification can usually easily define the transition region between crypt and villus, and counts were kept above this level. In each specimen 1000 epithelial cells were counted and the number and position of the lymphocytes in relation to the epithelial cell nuclei were noted. These two cell types were identified and easily distinguished by their nuclei which are characteristically different. The columnar cell nuclei are palestaining and more oval or elongated than those of lymphocytes which are smaller, round, and stain more darkly. Nuclei or nuclear fragments that could not be positively identified were ignored.

The position of the lymphocytes in relation to the epithelial cells (fig 1) was recorded as being basal if their nuclei lay adjacent to the epithelial connective tissue junction, perinuclear if they were above this basal position and apparently clustered around the epithelial nuclei, and supranuclear if they were entirely above the general level of the uppermost edge of the epithelial nuclei. In properly orientated sections there was usually no difficulty in assigning lymphocytes to these categories, but in random sections of any biopsy specimen there are usually a number of areas that are quite unsuitable for counting due to their obliquity (fig 2 ), and one must not 


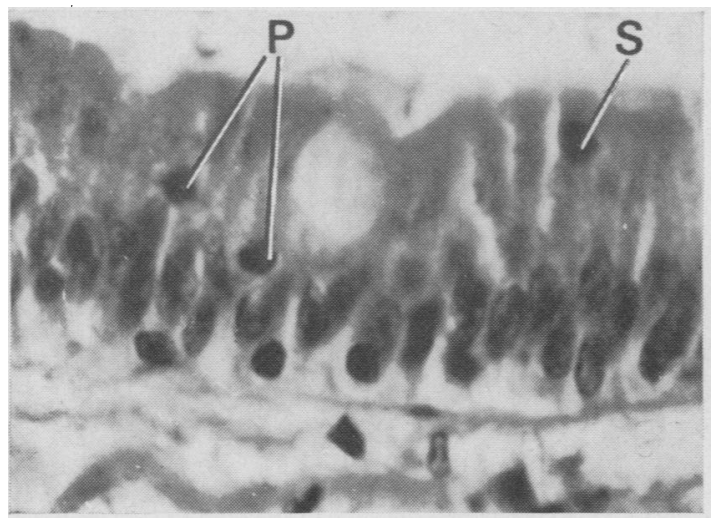

Fig 1

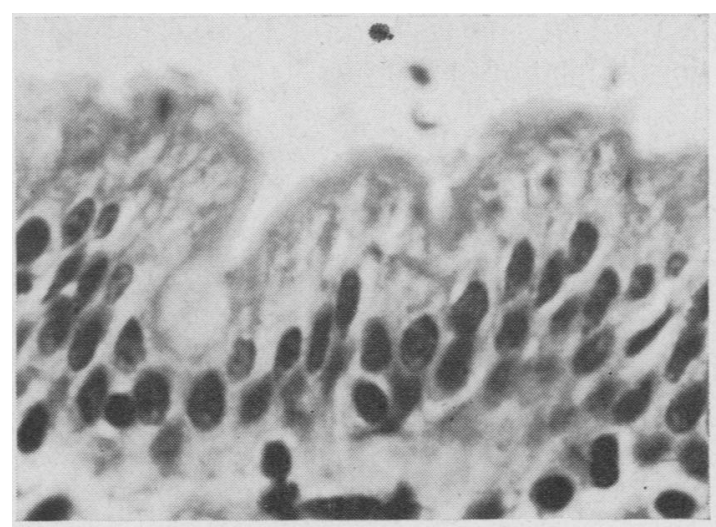

Fig 2

Fig 1 An example of intestinal epithelium showing lymphocytes in basal, perinuclear (P), and supranuclear (S) positions. With the section under the microscope and the possibility of going up and down through focus, the distinction between lymphocytic and epithelial nuclei is more easily made than from a static picture.

Fig 2 An example of obliquely sectioned epithelium that is unsuitable for counting.

expect to be able to count a thousand epithelial cells in continuity up and down the contiguous sides of adjacent villi. The total count will usually be made from varying lengths of epithelium from different parts of the specimen.

\section{Results}

MACROSCOPIC APPEARANCE

Of the 20 biopsies from the patients who did not have dermatitis herpetiformis (controls), three showed leaves only and 17 fingers and leaves. Among the 43 dermatitis herpetiformis biopsies, the mucosa was flat in 13 , convoluted in 10 , leaves only in eight, and fingers and leaves in 12.

\section{TOTAL LYMPHOCYTE COUNTS}

In the control group, the mean lymphocyte count per 1000 surface epithelial cells was $159 \pm$ SE 13 (range 69-285) (fig 3). Only four of the control subjects had counts greater than 200 . In the patients with dermatitis herpetiformis the mean lymphocyte count per 1000 epithelial cells was $464 \pm$ SE 27 (range 313-627) for the flat biopsies; $365 \pm$ SE 59 (range 130-739) for the convoluted biopsies; $535 \pm$ SE 39 (range 408-727) for the leaves only biopsies; and $301 \pm$ SE 31 (range 121-445) for the fingers and leaves biopsy specimens. All four macroscopic groups showed a highly significant difference in mean count compared with the control group $(P<0.001)$. Ten of the dermatitis herpetiformis patients had total counts less than 300 , in eight less than 285 , ie, within the control range, and three had counts less than 200 . Of these three patients, two showed fingers and leaves. The last one who had a convoluted biopsy had a reticulum cell sarcoma of the small intestine excised five years previously.

The group with the highest mean lymphocyte count was the leaves only group. However, this was

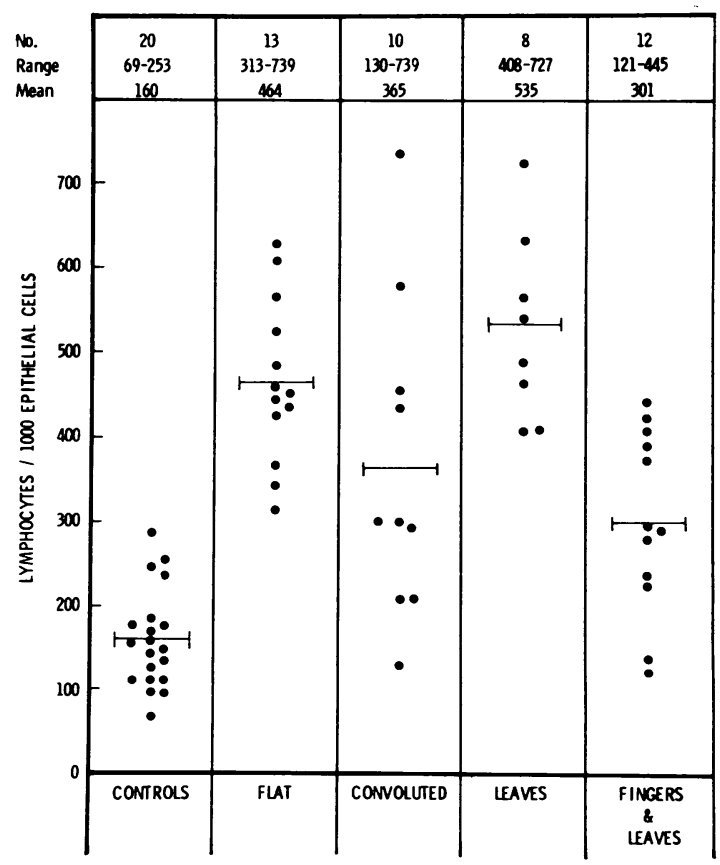

Fig 3 Macroscopic appearance of small intestinal mucosa in relation to total lymphocyte counts in control and dermatitis herpetiformis specimens. 
not significantly higher than the mean count for the flat biopsies ( $P>0 \cdot 10)$.

\section{POSITION OF THE INTRAEPITHELIAL} LYMPHOCYTES

\section{Basal position}

The mean number of lymphocytes per 1000 surface epithelial cells situated in the basal position was $79 \pm$ SE 8 (range 28-159) in the control group; $89 \pm$ SE 11 (range 43-191) in the flat biopsies; $93 \pm$ SE 12 (range 46-177) in the convoluted biopsies; $121 \pm$ SE 18 (range 43-205) in the leaves only biopsies; $98 \pm$ SE 13 (range 33-187) in the fingers and leaves biopsies (fig 4). There was no significant difference in the mean number of lymphocytes situated in the basal position between the control group and any of the dermatitis herpetiformis groups except the 'leaves' only group ( $P<0.02)$. There was no significant difference between the four dermatitis herpetiformis groups with regard to their mean basal lymphocyte counts.

\section{Perinuclear position}

The mean number of lymphocytes in the perinuclear position per 1000 epithelial cells was $81 \pm$ SE 7 (range 40-145) in the control group; $363 \pm$ SE 23 (range 252-532) in the flat biopsies; $251 \pm$ SE 46

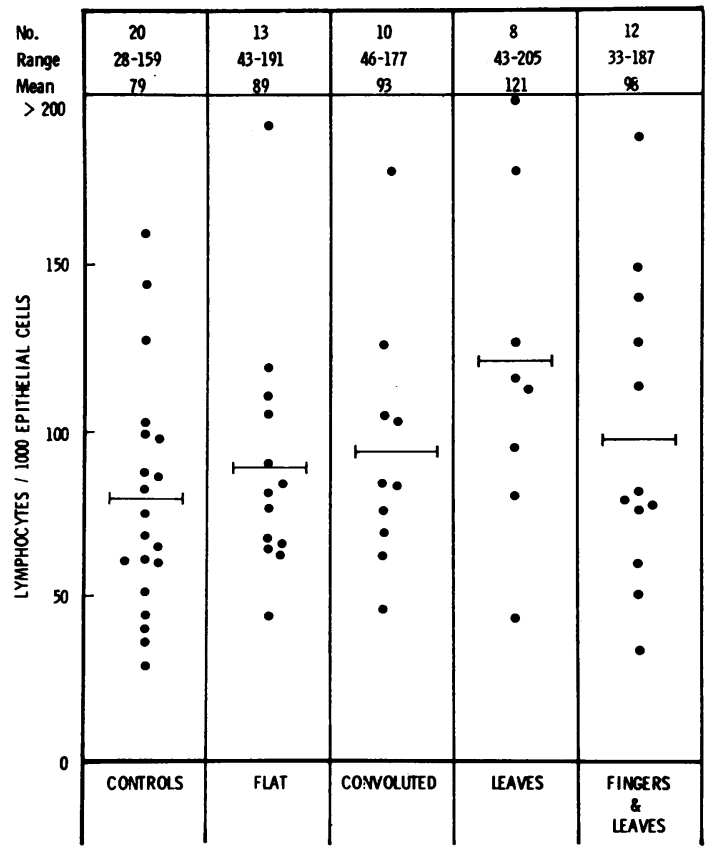

Fig 4 Basal lymphocyte count in relation to macroscopic appearance.

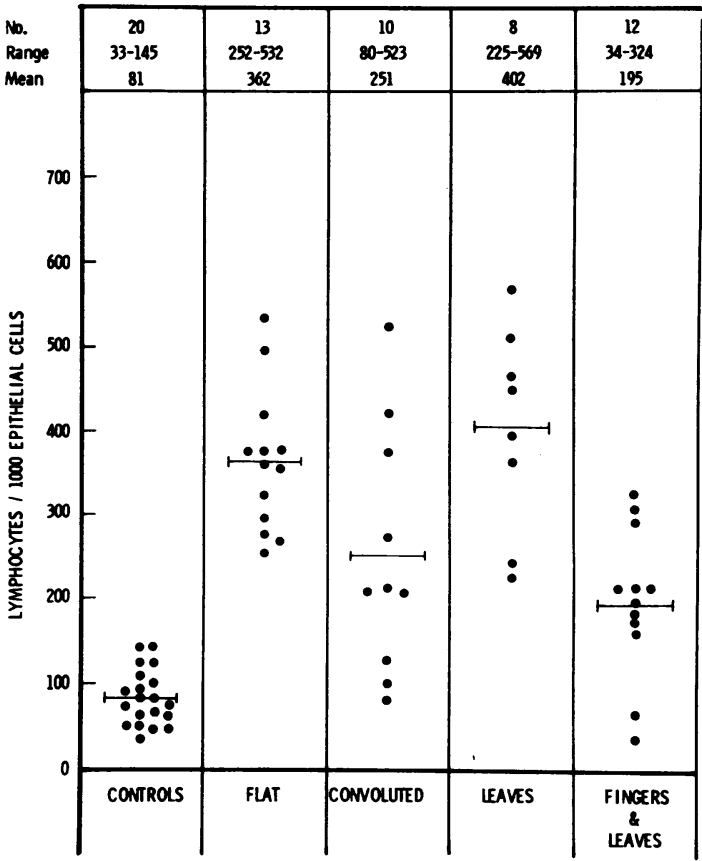

Fig 5 Perinuclear lymphocyte count in relation to macroscopic appearance.

(range 80-421) in the convoluted specimens; $402 \underset{ \pm}{\overrightarrow{ \pm}}$ SE43 (range 225-510) in the leaves only biopsies; and $195 \pm$ SE 25 (range 34-324) in the fingers and leaves $\stackrel{\square}{\square}$ biopsies (fig 5). Only five of the dermatitis herpeti- $\overrightarrow{\vec{a}}$ formis patients had perinuclear counts in the control 3 range (less than 145). Compared with the control $\rightleftharpoons$ group, the mean perinuclear lymphocyte count was significantly raised in each of the four dermatitis herpetiformis groups $(\mathrm{P}<0.001)$. The highest mean count for the dermatitis herpetiformis groups was in the leaves only specimens. There was, however, no significant difference between the mean perinuclear count in the flat biopsies and the leaves only group $(P>0 \cdot 30)$. The lowest mean count was in the fingers and leaves group but this was not significantly less than the next lowest group, the convoluted specimens $(P>0 \cdot 20)$.

\section{Supranuclear position}

The mean number of lymphocytes in the supra- $\omega$ nuclear position per 1000 epithelial cells was $0.55 \pm$ Q SE 0.22 (range 0-3) for the control group; $13.7 \pm \mathrm{SE}$ 2.3 (range 3-26) for the flat biopsies; $20 \cdot 1 \pm$ SE 6.9 (range 1-69) for the convoluted biopsies; $14.5 \pm$ SE 3.3 (range 4-29) for the leaves only biopsies; $8 \cdot 3 \pm$ SE 2.6 (range 0-25) for the fingers and leaves biopsies (fig 6). Eight of the dermatitis herpetiformis 


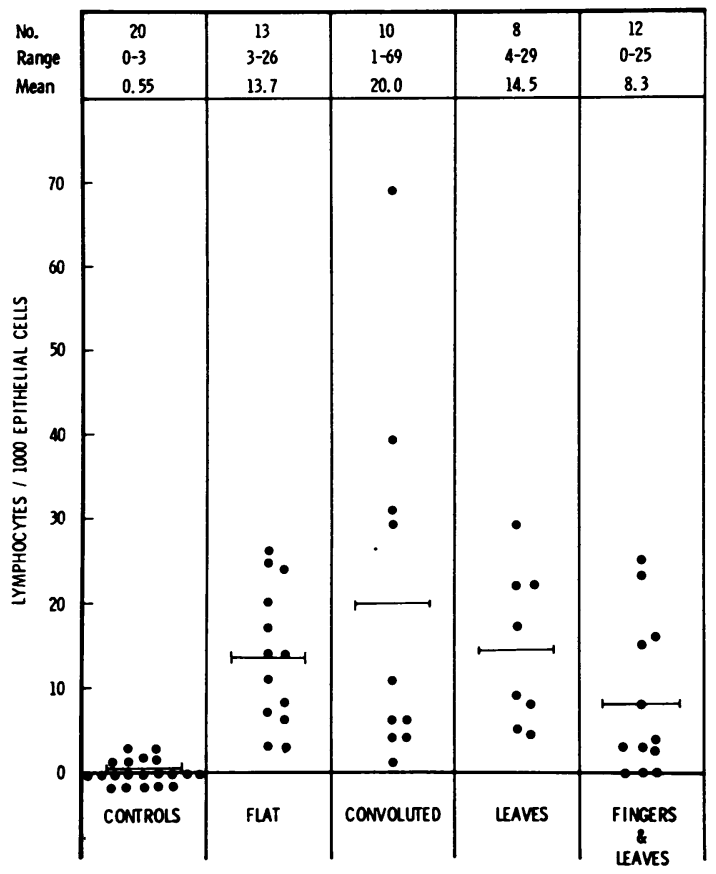

Fig 6 Supranuclear lymphocyte count in relation to macroscopic appearance.

patients showed supranuclear counts of 3 or less, ie, within the control range.

The mean supranuclear lymphocyte counts were significantly greater in all four dermatitis herpetiformis groups compared with the control ( $P<$ 0.001 ). There was no significant difference between any of the four dermatitis herpetiformis groups.

\section{RATIO AND SIGNIFICANCE OF BASAL TO}

PERINUCLEAR COUNTS

Among the control group the mean ratio of basal to perinuclear cells was $1: 1$, the lymphocytes being distributed equally between a basal and perinuclear position. However, in patients with dermatitis herpetiformis the increase in number of lymphocytes was due to an increase of lymphocytes in a perinuclear or supranuclear position. There was no increase in the number of lymphocytes in the basal position. Thus, the ratio of basal to perinuclear lymphocytes in patients with dermatitis herpetiformis was $1: 4$.

In six of the seven patients with dermatitis herpetiformis who had total counts below 285 , ie, within the normal range, the majority of the lymphocytes were situated in a perinuclear position, unlike the controls. The ratio of the basal to perinuclear counts was not 1:1 as in control specimens, but 1:4 as in dermatitis herpetiformis patients with higher total lymphocyte counts. In the three of the four control specimens with relatively high counts, ie, above 200 , the increase in number of lymphocytes occurred equally in the basal and perinuclear position, and the ratio of basal to perinuclear lymphocytes remained $1: 1$.

Thus, even when the total lymphocyte count is in a similar range in control and dermatitis herpetiformis patients, in the latter there are relatively more lymphocytes in the perinuclear than in the basal position.

\section{Discussion}

In this series of 43 patients with dermatitis herpetiformis, the incidence of abnormality of the small intestinal mucosa judged by macroscopic appearance according to the criteria of Booth, Stewart, Holmes, and Brackenbury (1962) on a single mucosal biopsy was only $54 \%$. Only 13 of our 43 patients $(31 \%)$ had a flat macroscopic appearance and a further $10(23 \%)$ had a convoluted appearance. Marks et al (1966), who first reported an abnormal small intestinal mucosa in dermatitis herpetiformis, found nine of their 12 patients $(75 \%)$ had an abnormal macroscopic appearance, whilst Fraser et al (1967) reported this abnormality in seven of their 12 patients $(58 \%)$. Fry et al (1967) found macroscopic abnormality in only four of their 12 patients $(33 \%)$. Brow et al (1970), using a multiple biopsy technique (six to eight biopsies in each patient), found an abnormal macroscopic mucosal appearance in each of the biopsies in 15 of their 22 patients $(69 \%)$, and an abnormal appearance in some of the multiple biopsies in a further six of their patients. Taken together, they were therefore able to demonstrate macroscopic mucosal abnormality in $21(95 \%)$ of their 22 patients. They postulated that the enteropathy in dermatitis herpetiformis was patchy and mild compared with that found in patients with coeliac disease. This suggestion is supported by the finding of a low incidence of clinical and laboratory evidence of malabsorption (Fry et al, 1967; Shuster et al, 1968; Marks and Whittle, 1969). It is now well established, however, that the enteropathy, although mild, is due to gluten sensitivity (Fry et al, 1968, 1969; Shuster et al, 1968; Weinstein, Brow, Parker, and Rubin, 1971).

The present study extends the work of Fry et al (1972), which showed that quantitative assessment of lymphocyte infiltration of the mucosal epithelium may be useful in the diagnosis of an enteropathy in dermatitis herpetiformis. In the present study, the range of lymphocyte counts for control series was 69-285 per 1000 epithelial cells compared with that 
of 6 to 40 per 100 epithelial cells reported by Ferguson and Murray (1971). In addition, our mean count was lower being $159 \pm$ SE 13 per 1000 epithelial cells whilst their mean was $21.1 \pm$ SD $7 \cdot 5$ per 100 epithelial cells. When performing lymphocyte counts it is important to appreciate, as observed by us and reported by Ferguson and Murray (1971), that there are always fewer lymphocytes towards the base of the villus compared with the top. Thus, counts performed mainly at the top of a villus will tend to be higher than counts around the base. The greater incidence of lymphocytes towards the tip of the villus compared to its base also occurs in coeliac disease (Ferguson and Murray, 1971). The higher lymphocyte count in the upper part of the villus may, in part, be explained by the fact that this is the part, rather than the base, which first comes into contact with the contents of the gut lumen, and is therefore the first to be challenged by substances being absorbed. We have attempted to overcome this problem of variation of the number of lymphocytes depending on which part of the villus is studied by counting the lymphocytes per 1000 epithelial cells. This covers a total of cells approximately equal to the number of one side of six or more villi, and, therefore, gives a more accurate estimation of the lymphocytic infiltration of the epithelium.

In the present study, irrespective of the macroscopic appearance, the intraepithelial lymphocyte count of the small intestinal mucosa was raised above the borderline range of $200 / 1000$ epithelial cells in all but three of our 43 patients. There was a highly significant difference between the mean counts for each of our four groups based on macroscopic appearance compared to our control series. Thus, irrespective of macroscopic appearance, the intraepithelial lymphocytes are usually increased in the small intestinal mucosa in dermatitis herpetiformis compared to normal. The increase in lymphocytes in the intestinal mucosa in both coeliac disease and dermatitis herpetiformis is probably a manifestation of gluten sensitivity. When patients with coeliac disease and dermatitis herpetiformis take a glutenfree diet, the lymphocyte count falls (Ferguson and Murray, 1971; Fry et al, 1972).

Three of our 43 patients with dermatitis herpetiformis had lymphocyte counts below 200 per 1000 epithelial cells which we take to be definitely in the normal range. Ferguson and Murray (1971) have one patient with coeliac disease who had a normal count. One of our three dermatitis herpetiformis patients has had a reticulum cell sarcoma removed from the small intestine, and another has now developed an unexplained and progressive peripheral neuropathy and the possibility of malignancy has to be considered. It is known that patients with gluten- sensitive enteropathy have an increased incidence of malignancy of the small intestine (Gough, Read, and Naish, 1962; Harris, Cooke, Thompson, and Waterhouse, 1967), and we wonder if the low lymphocyte count in the intestinal wall in some way is a reflection of impaired immunity predisposing to malignancy.

The present study shows that not only the numbers but also the distribution of lymphocytes may be important in the diagnosis of dermatitis herpetiformis. The number of lymphocytes in a 'basal' position was remarkably constant whether in the control group or in any of the four dermatitis herpetiformis groups classified on the macroscopic appearance. On the other hand, there were highly significant differences in the perinuclear and supranuclear counts of lymphocytes in all four dermatitis herpetiformis groups compared with the control group. In the control group the lymphocytes were equally distributed between basal and perinuclear positions and there were virtually no lymphocytes in the supranuclear position. In the patients with dermatitis herpetiformis, the predominant increase in the number of lymphocytes was in the perinuclear position in all four groups, but the presence of more than several lymphocytes in the supranuclear position per 1000 epithelial cells was also confined to dermatitis herpetiformis biopsies. Thus, in deciding whether a? small intestinal biopsy shows evidence of gluten ro sensitive enteropathy, it is apparent that the macro-? scopic appearance is no longer a strict enough criterion, as previously suggested (Fry et al, 1972). An increase in the number of lymphocytes in the intestinal epithelium appears to be a more sensitive indication of gluten-sensitive enteropathy. It is also apparent from this study that the increase in the lymphocytes in gluten-sensitive enteropathy in dermatitis herpetiformis is predominantly in the perinuclear position.

It is uncertain why the increase in the number of lymphocytes in gluten-sensitive enteropathy takes place in the perinuclear or supranuclear positions in the epithelium. It is well established from electron microscope studies (Meader and Landers, 1967; Toner and Ferguson, 1971) that the lymphocytes in both the normal gut and in gluten-sensitive enteropathy are within the epithelial layer, ie, intraepithelial, but extracellular in relation to the epithelial cells; they are therefore properly called intercellular but not intracellular. There are a number of possibilities as to why the increased number of lymphocytes is predominantly perinuclear in glutensensitive enteropathy. First, lymphocytes in glutensensitive enteropathy would theoretically be pushed away from the basal membrane because of a mechanical effect, the lymphocytes being forced into a higher position simply because the basal region cannot physically accommodate more than a certain 
number. However, this does not explain why more lymphocytes than usual are entering the intercellular spaces from the underlying connective tissue in the first place. No information is available on the relationship of the lymphocyte population in the epithelium to that of the lamina propria, but it is unlikely that the latter becomes so full of lymphocytes that they spill over into the epithelium. There is often a visual impression that the lamina propria is by no means overpopulated with lymphocytes when the epithelium is heavily infiltrated, but this must remain only an unconfirmed impression until figures are available for connective tissue lymphocytes - and this is much more difficult to assess than the estimation of epithelial infiltration.

Secondly, the lymphocytes may rise to a higher position due to an antigenic stimulus from gluten, either in the intestinal lumen or after absorption by the epithelial cells. Even when there is heavy infiltration and the epithelium remains columnar, there are relatively few lymphocytes in the supranuclear position. This may be a purely physical phenomenon since, although a considerable increase in the volume of the intercellular spaces is possible between the lower three-quarters or so of epithelial cells (as occurs, for example, during fluid absorption), the apices remain closely adjacent because of the concentration of intercellular attachments (tight junctions and intermediate junctions) in this area. In biopsies with cuboidal epithelium, hardly any lymphocytes fall within our definition of supranuclear, since there is just not enough space between the top of the nucleus and the apex.

Thirdly, in gluten-sensitive enteropathy the epithelial cells themselves may exert a chemotactic influence on lymphocytes and so attract them to a higher than normal position, perhaps because of substances produced by the epithelial cell under the influence of its own nucleus. It is also possible that the lymphocytes are engaged in exchange of materials with the epithelium or vice versa. Thus, the nearer the respective nuclei are to one another, the more quickly can the nucleocytoplasmic interchange and passage of information within each cell be effected. However, although small molecules may pass between epithelial cells and lymphocytes through their adjacent plasma membranes, the two cell types always remain distinct from one another, without any cytoplasmic continuity or specialized regions of attachment (Toner and Ferguson, 1971). It is not known for how long lymphocytes remain among the epithelial cells, but it must not be assumed that they all move up with the epithelial sheet to be shed into the lumen.

At all events, the findings in this study, taken together with those of Brow et al (1971), and
Weinstein (1973), do not support the concept of Gebhard et al (1973) that there are two groups of patients with dermatitis herpetiformis-those with gastrointestinal abnormality and those without. Rather, it would appear that virtually all patients with dermatitis herpetiformis do in fact have glutensensitive enteropathy and that in approximately half of them the disease is so mild that there is no macroscopic abnormality of the small intestinal mucosa on a single biopsy. However, there is an increase in the lymphocytes in the intestinal epithelium in over $90 \%$ of patients with dermatitis herpetiformis in a single jejunal biopsy and this increase is mainly in the perinuclear position. The findings here support the concept that dermatitis herpetiformis is essentially an immunological disorder of the skin and small intestine, and increase in the lymphocytes in the small intestinal mucosa is a further manifestation of this disorder.

We are most grateful to Dr Etain Cronin, Dr Suzanne Alexander, Dr R. J. Cairns, and Dr J. J. Cream for referring patients.

L.F. and P.P.S. are in receipt of grants from the MRC and Wellcome Trust.

\section{References}

Booth, C. C., Stewart, J. S., Holmes, R., and Brackenbury, W. (1962). Dissecting microscope appearance of intestinal mucosa. In Intestinal Biopsy (Ciba Foundation Study Group No. 14), edited by G. E. W. Wolstenholme and M. P. Cameron, pp. 2-23. Churchill, London.

Brow, J. R., Parker, F., Weinstein, W. M., and Rubin, C. E. (1971). The small intestinal mucosa in dermatitis herpetiformis. 1. Severity and distribution of the small intestinal lesion and associated malabsorption. Gastroenterology, 60, 355-361.

Ferguson, A., and Murray, D. (1971). Quantitation of intraepithelial lymphocytes in human jejunum. Gut, 12, 988-994.

Fraser, N. G., Murray, D., and Alexander, J. O'D. (1967). Structure and function of the small intestine in dermatitis herpetiformis. Brit. J. Derm., 79, 509-518.

Fry, L., Keir, P., McMinn, R. M. H., Cowan, J. D., and Hoffbrand, A. V. (1967). Small-intestinal structure and function and haematological changes in dermatitis herpetiformis. Lancet, 2, 729-734.

Fry, L., McMinn, R. M. H., Cowan, J. D., and Hoffbrand, A. V. (1968). Effect of gluten-free diet on dermatological, intestinal, and haematological manifestations of dermatitis herpetiformis. Lancet, 1, 557-561.

Fry, L., McMinn, R. M. H., Cowan, J. D., and Hoffbrand, A. V. (1969). Gluten-free diet and reintroduction of gluten in dermatitis herpetiformis. Arch. Derm. 100, 129-135.

Fry, L., and Seah, P. P. (1974). Dermatitis herpetiformis: an evaluation of diagnostic criteria. Brit. J. Derm., 90, 137-146.

Fry, L., Seah, P. P., McMinn, R. M. H., and Hoff brand, A. V. (1972) Lymphocytic infiltration of epithelium in diagnosis of glutensensitive enteropathy. Brit. med. J., 3, 371-374.

Gebhard, R. L., Katz, S. I., Marks, J., Shuster, S., Trapani, R. J., Rogentine, G. N., and Strober, W. (1973). HL-A antigen type and small-intestinal disease in dermatitis he rpetiformis. Lancet 2, 760-762.

Gough, K. R., Read, A. E., and Naish, J. M. (1962). Intestinal reticulosis as a complication of idiopathic steatorrhoea. Gut, 3, 232-239.

Harris, O. D., Cooke, W. T., Thompson, H., and Waterhouse, J. A. H. (1967). Malignancy in adult coeliac disease and idiopathic steatorrhoea. Amer. J. Med., 42, 899-912. 
Marks, J., Shuster, S., and Watson, A. J. (1966). Small-bowel changes in dermatitis herpetiformis. Lancet, 2, 1280-1282.

Marks, R., and Whittle, M. W. (1969). Results of treatment of dermatitis herpetiformis with a gluten-free diet after one year. Brit. med. J., 4, 772-775.

Meader, R. D., and Landers, D. F. (1967). Electron and light microscopic observations on relationships between lymphocytes and intestinal epithelium. Amer. J. Anat., 121, 763-774.

Seah, P. P., Fry, L., Mazaheri, M. R., Mowbray, J. F., Hoffbrand, A. V., and Holborow, E. J. (1973). Alternate-pathway complement fixation by IgA in the skin in dermatitis herpetiformis.
Lancet, 2, 175-177.

Shuster, S., Watson, A. J., and Marks, J. (1968). Coeliac syndrome in dermatitis herpetiformis. Lancet, 1, 1101-1106.

Toner, P. G., and Ferguson, A. (1971). Intraepithelial cells in the human intestinal mucosa. J. ultrastruct. Res., 34, 329-344.

Weinstein, W. M. (1973). Latent celiac sprue. (Abstr.) Gastroenterology, 64, 819.

Weinstein, W. M., Brow, J. R., Parker, F., and Rubin, C. E. (1971). The small intestinal mucosa in dermatitis herpetiformis. II. Relationship of the small intestinal lesion to gluten. Gastroenterology, 60, 362-369.

\section{Reports and Bulletins prepared by the Association of Clinical Biochemists}

The following reports and bulletins are published by the Association of Clinical Biochemists. They may be obtained from The Publishing Department, British Medical Journal (ACB Technical Bulletins), B.M.A. House, Tavistock Square, London WC1H 9JR. Overseas readers should remit by British Postal or Money Order.

\section{SCIENTIFIC REPORTS (price $£ 1 \cdot 00 / \$ 2.00$ each)}

3 Automatic Dispensing Pipettes: an assessment of 35 commercial instruments September 1967 P. M. G. BROUGHTON, A. H. GOWENLOCK, G. M. WIDDOWSON, and K. A. AHLQUIST

4 An Evaluation of five Commercial Flame Photometers suitable for the Simultaneous Determination of Sodium and Potassium March 1970 P. M. G. BROUGHTON and J. B. DAWSON

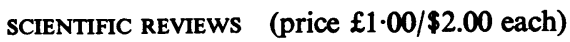

1 The Assessment of Thyroid Function March 1971 F. V. FLYNN and J. R. HOBBS

2 Renal Function Tests Suitable for Clinical Practice January 1972 F. L. MITCHELl, N. VEALL, and R. W. E. WATTS

TECHNICAL BULLETINS (price $£ 1 \cdot 00 / \$ 2.00$ each)

9 Determination of Urea by AutoAnalyzer November 1966 RUTH M. HASLAM

11 Determination of Serum Albumin by AutoAnalyzer using Bromocresol Green October 1967 B. E. NORTHAM and G. M. WIDDOwson

13 An Assessment of the Technicon Type II Sampler Unit March 1968 B. C. GRAY and G. K. MGGOWAN

14 Atomic Absorption Spectroscopy: an outline of its principles and a guide to the selection of instruments May 1968 J. B. DAWSON and P. M. G. BROUGHTON

15 A Guide to Automatic Pipettes (2nd edition) June 1968 P. M. G. BROUGHTON

16 A Guide to Automation in Clinical Chemistry May 1969 P. M. G. BROUGHTON

17 Flame Photometers: a comparative list of 17 instruments readily available in Britain August 1969 P. WILDING
19 Spectrophotometers: a comparative list of low-priced instruments readily available in Britain May 1970 C. E. WILDE and P. SEWELL

20 Quantities and Units in Clinical Biochemistry June 1970 P. M. G. BROUGHTON

21 Filter Fluorimeters: A comparative list of 18 instruments September 1970 H. BRAUNSBERG and S. S. BROWN

22 Bilirubin Standards and the Determination of Bilirubi by Manual and Technicon AutoAnalyzer Methods January 1971 BARBARA BILLING, RUTH HASLAM, and N. WALD

23 Interchangeable Cells for Spectrophotometers and Fluorimeters September 1971 S. S. BROWN and A. H. GOWENLOCK

24 Simple Tests to Detect Poisons March 1972 B. W. MEADE et al.

25 Blood Gas Analysers May 1972 K. DIxoN

26 Kits for Enzyme Activity Determination September 1972 S. B. ROSALKI and D. TARLOW

27 Assessment of Pumps Suitable for Incorporation into Existing Continuous Flow Analytical Systems November 1972 A. FLECK et al.

28 Routine Clinical Measurements of Transferrin in Human Serum September 1973 K. DIXON

29 Control Materials for Clinical Biochemistry (5th edition) September 1973 J. F. STEVENS

30 Notes on the Quality of Performance of Serum Cholesterol Assays September 1973 s. S. BROWN 